\title{
Effects of Rubber Crumbs, Plastic Powder and Paper Sludge on Swelling Behaviourof Expansive Soil
}

\author{
S.Janaki Raman, Santhosh G, Andrew Hutson T, Surya A , Vijay Antony Raj S
}

\begin{abstract}
The expansive soil is a type of organic clay soil with medium to high compressibility which expands when meet with water and shrinks when the water evaporates. It expands during the rainy season due to intake of water and shrinks during the summer season. It possess low strength and undergoes excessive volume changes, making their use in the constructions very difficult. The stabilization is required to improve the above stated properties. A lot of damages occurs to structures founded on this type of soil. The aim of the study was to reduce the swell percentage and increase the strength (Unconfined Compressive Strength) of the expansive soil with the use of waste materials. Experiments were carried out in the given sample by adding combination of Rubber Crumbs, Paper sludge, Plastic powder. Experiments were carried out in the given sample by adding combination of Rubber Crumbs, Paper sludge, Plastic powder. The clay soil is stabilized using three different waste material under different proportions in which $5 \%$ of rubber crumbs and $5 \%$ of plastic powder gives good results and combination of the two gives good improvements in strength as well as the swelling behavior of soil.
\end{abstract}

\section{INTRODUCTION}

Expansive soils in many parts of the India pose a significant hazard to foundations for light buildings. Swelling clays derived from residual soils can exert uplift pressures. Expansive soils owe their characteristics to the presence of swelling clay minerals. As they get wet, the clay minerals absorb water molecules and expand; conversely, as they dry they shrink, leaving large voids in the soil. Swelling clays can control the behaviour of virtually any type of soil if the percentage of clay is more than about 5 percent by weight. Soils with smectite clay minerals, such as montmorillonite, exhibit the most profound swelling properties.

Potentially expansive soils can typically be recognized in the lab by their plastic properties. Organic clays of high plasticity, generally those with liquid limits exceeding 50 percent and plasticity index over 30 usually have high inherent swelling capacity. Expansion of soils can also be measured in the lab directly, by immersing a remoulded soil sample and measuring its volume change.

In the field, expansive clay soils can be easily recognized in the dry season by the deep cracks, in roughly polygonal

Revised Manuscript Received on April 12, 2019.

S.Janaki Raman,Asst Prof, Dept of civil engineering, KITS,Coimbatore, Tamil Nadu, India.(raman26892@gmail.com)

Santhosh G,Students, Dept of civil engineering, KITS,Coimbatore, Tamil Nadu, India.

Andrew Hutson T,Students, Dept of civil engineering, KITS,Coimbatore, Tamil Nadu, India.

Surya A,Students, Dept of civil engineering, KITS,Coimbatore, Tamil Nadu, India.

Vijay Antony Raj SStudents, Dept of civil engineering, KITS,Coimbatore, Tamil Nadu, India. patterns, in the ground surface. The zone of seasonal moisture content fluctuation can extend from three to forty feet deep. This creates cyclic shrink/swell behaviour in the upper portion of the soil column, and cracks can extend to much greater depths than imagined by most engineers.

The most obvious way in which expansive soils can damage foundations is by uplift as they swell with moisture increases. Swelling soils lift and crack lightly-loaded, continuous strip footings, and frequently cause distress in floor slabs.

Because of the different building loads on different portions of a structure's foundation, the resultant uplift will vary in different areas. As shown in Fig. 3, the exterior corners of a uniformly-loaded rectangular slab foundation will only exert about one-fourth of the normal pressure on a swelling soil of that exerted at the centre

\section{LITERATURE REVIEW}

(Ms.L.Kokila .et al 2017), The benefits of reusing scrap tyres are particularly enhanced if they can be used to replace (fully or partially) scarce and valuable virgin construction materials which are non-renewable. . Studies on compressibility performance 5 of sand with and without tire derived mixture and observed that the tyre derived aggregate was more compressible than sand, and the addition of sand of $15 \%$ to $35 \%$ reduces the compressibility of rubber derived aggregate by around $50 \%$. CBR tests conducted on the soil measure the strength of a sub-grade material as compared to a standard dense graded aggregate The CBR value for both the soils increased upto the addition of $10 \%$ crumb rubber powder which it started decreasing

(SParveen Kumar et.al. 2017) hriganeshshinde, G.K Patil (2016) The agricultural such as rice husk or ground nut shell but due to its property of decomposing if its not possible to utilize it in its pure form hence we have to use ashes of these waste materials separately at $3 \%, 6 \% 9 \%$ and $15 \%$ and carried out test such as CBR and standard proctor test for each percent Hence there is a value addition to these two agricultural waste serving the three benefits of safe disposal of wastes, using a stabilizer and return of income on it. The foundation and pavement is very sensitive to the characteristics which provide the support for pavement or structure and problems associated with this further become more critical particularly in regions where the black cotton soil are there.

Athira, Sowmya v krishnankutty(2017) The improvement 
of compressive strength of expansive soil when stabilized with different dosages of coconut powder $(0 \%, 3 \%, 6 \%, 9 \%$ and $12 \%)$ and lime $(3 \%, 6 \%$ and $9 \%)$. The test were conducted various dosages of coconut shell powder and lime after curing periods of 0,7 and 28 day in order to study the drying and wetting properties. From the results we inferred that coconut shell powder and lime are effective in improving the properties of expansive soil.Expansive soils are fine grained soil or decomposed rocks that show huge volume change when exposed to the fluctuations of moisture content. The expansive soils are mostly likely to be unsaturated and have montmorillonite clay minerals. Most of severe damage in relation to expansive soil is dependent on the amount of mono valentcations absorbed to the clay minerals. These makes the necessity to stability the soil before the commencement of construction works. Thus the stabilization of expansive soil is important in various geotechnical engineering works such as building foundation, pavement structures, irrigation system etc. to reduce the alternate swelling and shrinkage of expansive soil. Many soil stabilizers such as coconut shell powder and lime are used for the stabilization. Swelling index test was conducted to identify the soil as expansive. All engineering properties of the soil sample is determined. The increase in compressive strength and the maximum dry density of the soil sample with the addiction of stabilizers.

Aditya Kumar Anupama, Praveen Kumar (2013) Present investigation describes the behavioural aspect of soils mixed with industrial waste materials viz. fly ash (FA), rice husk ash (RHA) \& bagasse ash (BA) and agricultural waste material rice straw ash (RSA) to improve the load bearing capacity of the soil. Clayey soil has been considered using four different types of stabilizer viz. FA, BA, RHA \& RSA ranging from 5 to $35 \%$ by weight of soil. The physical and chemical properties of these stabilizers were ascertained and compared. The soil admixed with FA, BA, RHA and RSA samples were cured up to 28 days before testing. Various tests like shrinkage limit, CBR, UCS, and triaxial test were conducted. Marked improvements in shrinkage limits were observed for soil admixed with FA, BA, RHA and RSA. This improvement was more pronounced for $30 \%$ RHA admixing. Admixing of FA, BA, RHA and RSA made to have higher optimum moisture content as the dosages of stabilizers increased. This increase was more pronounced for RHA admixed soil-mixtures in comparison to that of other stabilizers.

Chashoengtanbinsh, China(2015) In the present investigation, 12 groups of soil samples were prepared at three different percentages of PP-fiber content (i.e. 0.05\%, $0.15 \%$ and $0.25 \%$ by weight of soil) and two different percentages of cement content (i.e. $5 \%$ and $8 \%$ by weight of soil), and unconfined compression and direct shear tests were carried out after 7-, 14- and 28-day curing periods. The test results indicated that the inclusion of fiber reinforcement within uncemented and cemented soil caused an increase in the unconfined compressive strength (UCS), shear strength and axial strain at failure, decreased the stiffness and the loss of post-peak strength, and changed the cemented soil's brittle behavior to a more ductile one. The interactions at the interface between fiber surface and soil matrix were analyzed by using scanning electron microscopy (SEM). It is found that the bond strength and friction at the interface seem to be the dominant mechanism controlling the reinforcement benefit.

\section{OBJECTIVE}

1.To find the natural shear strength and swelling character and behaviour of expansive under various circumstance.

2.To find the appropriate stabilizing material for the stabilization of expansive soil.

3.To comparative analyze the various proportion of stabilizing material to reduce the swelling behaviour of soil.

\section{METHODOLOGY \& RESULTUS}

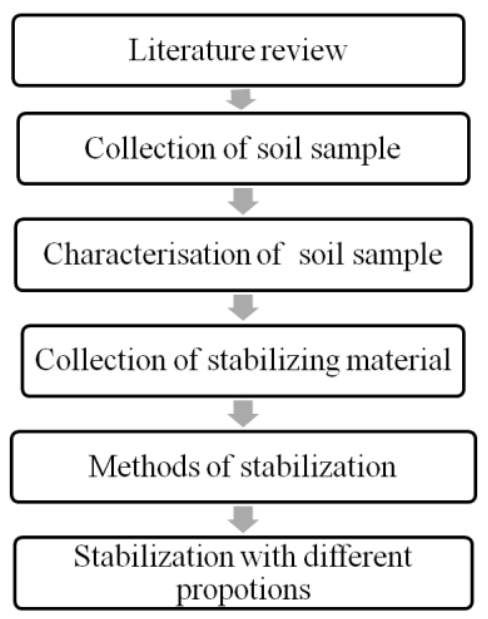

Clay soil is extensively known for high swelling behavior. This expansive clay soil considered for this research work and the soil samples were collected from Vellore district. Materials such as rubber crumb, paper sludge and plastic powder are used.

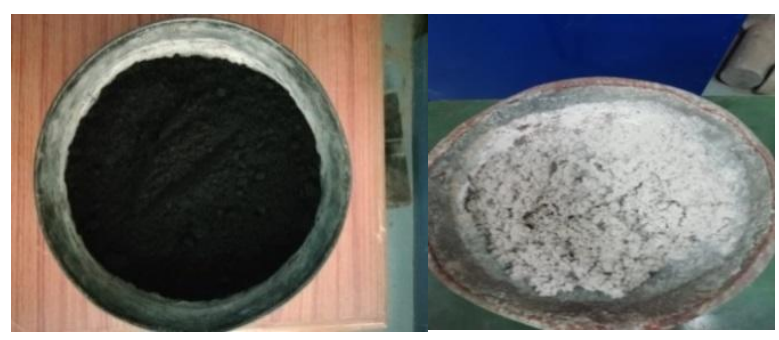

Fig .1 Rubber crumbs Fig.2 Paper sludge

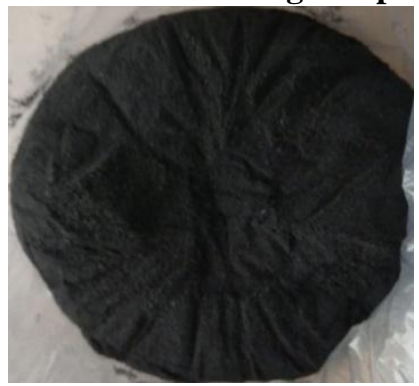

Fig. 3 Plastic powder

Published By:

Blue Eyes Intelligence Engineering

\& Sciences Publication 
The soil sample was tested for the index properties and the results were given below

Table 1 Observation of sieve analysis sample

\begin{tabular}{|l|l|}
\hline TYPES & SOIL SAMPLE 1 \\
\hline D10 & 0.17 \\
\hline D30 & 0.45 \\
\hline D60 & 0.79 \\
\hline $\mathrm{Cu}$ & 4.64 \\
\hline $\mathrm{Cc}$ & 1.507 \\
\hline GRAVEL (\%) & 7.9 \\
\hline COARSE SAND & 21.9 \\
\hline MEDIUM SAND & 43.5 \\
\hline FINE SAND & 24.2 \\
\hline SILT \& CLAY & 2.7 \\
\hline
\end{tabular}

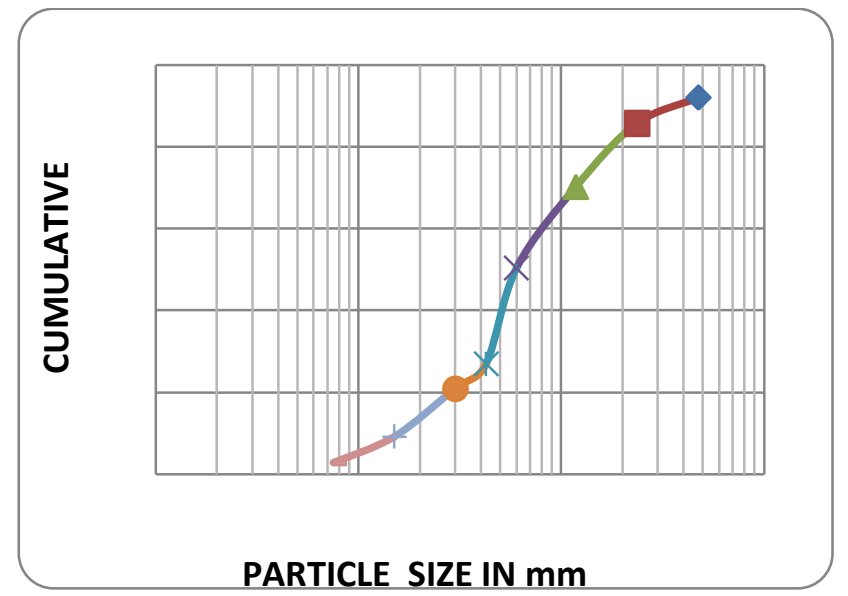

Fig. 4 Sieve graph

\section{Atterberg's limit}

Ip $=$ Liquid Limit - Plastic Limit

Soil Sample $=70-31.33=38.67$

Flow Index

If $=(72.3-70) /(1.39-1.8)=10.45$

Toughness Index

$\mathrm{It}=\mathrm{Ip} / \mathrm{If}=3.667$

The Shrinkage Limit Of Clay Soil Is 55\%

The soil was experimented with the expansive nature of the sample and it is influenced by deferent proportions of the reinforcing materials such as rubber crumbs, plastic powder and paper sludge in 5\%,5\%, 2.5\% And 1:2 ratio vice versa

\section{SWELL PRESSURE:}

The free swell index of the soil sample is $55 \%$

The swell pressure

for clay soil , $\mathrm{P}=40.76 \mathrm{kN} / \mathrm{m}^{2}$

The swell pressure

for soil +rubber $\operatorname{crumb}(5 \%), \mathrm{p}=9.68 \mathrm{kN} / \mathrm{m}^{2}$

The swell pressure $\mathrm{f}$

or soil +paper sludge $(2.5 \%), \mathrm{p}=43.56 \mathrm{kN} / \mathrm{m}^{2}$

The swell pressure

for soil + rubber crumb(5\%) +paper sludge $(2.5 \%)$, $\mathrm{p}=38.21 \mathrm{kN} / \mathrm{m}^{2}$

The swell pressure

or soil + plastic +rubber crumb, $\mathrm{p}=5.35 \mathrm{kN} / \mathrm{m}^{2}$

Consolidation test results:
The soil sample was tested with theplastic powder and rubber crumb in which the swelling behavior is reduced to higher value.

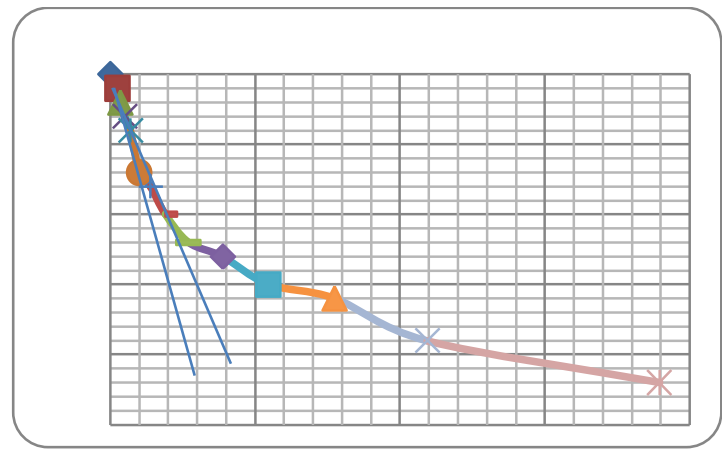

Fig. 5. $\sqrt{\text { tvs }} \Delta \mathrm{H}$ cumulative graph

The consolidation coefficient $\mathrm{C}_{\mathrm{v}}=\quad \mathrm{T}_{90} \mathrm{~d}^{2} / \mathrm{t}_{90}=0.032$ $\mathrm{cm}^{2} / \mathrm{min}$

\section{UNCONFINED COMPRESSION TEST:}

Even though the soil sample was tested for reduction in swelling behavior we had also conscious not to reduce the shear strength of the soil so we have tested the Unconfined compressive strength of the soil sample in all the reinforcement ratios of deferent material

Cohesive strength of clay soil.c $=33.5 \mathrm{kpa}$

The unconfined compression strength of clay soil + plastic, $\mathrm{q}_{\mathrm{u}}=91 \mathrm{kpa}$

The unconfined compression strength of clay soil+ paper sludge $=96 \mathrm{kpa}$

The unconfined compression strength of clay soil + plastic +rubber $\mathrm{q}_{\mathrm{u}}=88 \mathrm{kpa}$

The unconfined compression strength of clay soil+ paper sludge +rubber $\mathrm{q}_{\mathrm{u}}=44 \mathrm{kpa}$

The unconfinedcompressive strength of soil + rubber $\mathrm{q}_{\mathrm{u}}=52 \mathrm{kpa}$

\section{CONCLUSION:}

Since the main objective of this project is to reduce swelling nature of expansive soil we had to use waste materials to reduce its strength. It is found that paper sludge performs better strength then plastic powder and rubber crumb .It is biodegradable and also it shows very less perfomance in swelling behaviour. We choose a set of combination plastic with paper, plastic with rubber; rubber with paper respectively. Among these propotions the plastic with rubber gives ultimate strength of $88 \mathrm{Kpa} \&$ reduced swellingness of $5.35 \mathrm{kN} / \mathrm{m}^{2}$

\section{REFERENCES}

1. Experimental Investigation on Soil Stabilisation Using Rubber Crumbs on Expansive Soil s.L.Kokila, G.Bhavithra, V.Hemapriya, C.Iniya, P.Madhunigga World Journal of Research and Review (WJRR)ISSN:2455-3956, Volume-4, Issue-4, April 2017 Pages 16-19

2. Stabilization of Soil Using Crumb Rubber Parveen Kumar, Dr. Rajesh Goel, Vishal Yadav ICETETSM-17 ISBN978-9386171-60-3

Published By: 
3. Effect of Addition of Waste Tyre Crumb Rubber on Weak Soil StabilisationFebruary 2016Indian Journal of Science and Technology 9(5)DOI: 10.17485/ijst/2016/v9i5/87259

4. Stabilization Of Expansive Soil Using Crumb Rubber Powder And Cement January 2016 IJIRT Volume 2 Issue 8 ISSN: 2349-6002

5. SOFT Soil Subgrade Stabilization Using Waste Paper Sludge Ash (WPSA) MixturesJanuary 2015DOI: 10.1007/978-981287-290-6_38 